\title{
Tube expansion and diffusion bonding of 316L stainless steel tube-to-tube sheet joints using a commercial roller tube expander
}

\author{
Nils Haneklaus ${ }^{1}$, Rony Reuven ${ }^{1,2}$, Cristian Cionea ${ }^{1}$, \\ Peter Hosemann ${ }^{1}$, Per F. Peterson ${ }^{1}$ \\ ${ }^{1}$ Department of Nuclear Engineering, University of California, Berkeley, \\ 4118 Etcheverry Hall, MC 1730, Berkeley, CA 94720-1730, USA \\ ${ }^{2}$ N.R.C.N, P.O. Box 9001, Beer-Sheva, Israel
}

Keywords: Tube expansion, diffusion bonding, 316L stainless steel, tube-to-tube sheet joints

\begin{abstract}
Diffusion bonding is a solid-state welding technique to join metallic and non-metallic materials. Due to geometrical considerations, fabrication and possible materials choices diffusion bonding was chosen here to support tube-to-tube sheet joints of large coil-wound heat exchangers (CWHE) made from 316L stainless steel. In contrast to traditional diffusion bonding where pressure is applied constantly during heat treatment, pressure is applied here initially prior to heat treatment using a commercial three roller tube expander. Processing parameters of this novel approach are presented in this study. Mechanical pull-out tests were conducted to evaluate if the manufactured joints are sufficiently bond to guarantee safe operation of the device. It was found that diffusion bonding followed tube expansion increases the pull-out force nearly threefold from a mean of $3.4 \mathrm{kN}$ to $9.2 \mathrm{kN}$ at which level the tube ruptures so that higher loads could not be measured. Tube-to-tube sheet joints fabricated using tube expansion and diffusion bonding met the engineering requirement, tube rupture against mechanical pull-out, set for this study.
\end{abstract}

\section{$1 \quad$ Introduction}

The Department of Nuclear Engineering at the University of California, Berkeley (UCB) is developing a coil wound heat exchanger (CWHE) design that supports the use of gas Brayton power conversion for thermal power production. Based on the Advanced High Temperature Reactor (AHTR) described by Forsberg et al. (2003) UCB developed the Mark-1 Fluoride-saltcooled High-temperature Reactor (Mk-1 FHR) with CWHE that is described in one of UCBs reports (UCBTH-14-002, 2014). In the initial design heat is transferred from a low pressure fluoride salt coolant (at approx. 0.1 MPa) to compressed air (at approx. 1.8 $\mathrm{MPa}$ ) and the used CWHEs were correctly coined coil tube gas heaters (CTGHs). A key alternative heat exchanger design would use supercritical carbon dioxide $\left(\mathrm{S}-\mathrm{CO}_{2}\right)$ instead of air with sodium at up to $700{ }^{\circ} \mathrm{C}$ as the primary coolant and requires operation at even higher pressures of $20 \mathrm{MPa}$ or more, with the coolant at a low pressure of approx. $0.1 \mathrm{MPa}$. In contrast to pressurized water reactor heat 
exchanger tubes that experience internal pressure the tubes in the foreseen heat exchanger design experience external pressure.

UCB has developed different diffusion bonding techniques to fabricate $316 \mathrm{~L}$ stainless steel tubeto-tube sheet joint test samples representative of the final heat exchanger design: press fitting and diffusion bonding developed by Buster et al. (UCBTH-14-005, 2014), thermal fitting and diffusion bonding, hybrid friction diffusion bonding as well as tube expansion and diffusion bonding that was briefly introduced by Haneklaus et al. (2015). A developed method was considered successful if the tube would rupture during tensile-pull out testing. Massey and Jones (2012) describe tube pull-out testing as an "established method" to determine the quality of a joint between tube and tube-sheet that is particularly well suited for roller expanded joints. Kikuchi et al. (2010) used the same criteria to determine the quality of welded tube-to-tube sheet joints for the heat exchanger of the Japan Sodium-cooled Fast Reactor (JSFR) that has to withstand pressure differences similar to the ones foreseen in the FHR design with $\mathrm{S}-\mathrm{CO}_{2}$ cycle. This work outlines how a commercial roller tube expander was used to develop the initial pressure required for subsequent partial diffusion bonding of tube and tube-sheet. Three engineering parameters:

- Applied pressure during tube expansion

- Surface treatment prior to tube expansion

- $\quad$ Time/Temperature of the heat treatment

were found to be of particular importance for this new manufacturing process. Their influence on the joints quality are discussed in this study.

\section{Experimental procedure}

The heat exchanger tube is simulated by a $76.2 \mathrm{~mm}$ long tube (OD: $6.35 \mathrm{~mm}$, ID: $4.57 \mathrm{~mm}$ ) made from corrosion resistant $316 \mathrm{~L}$ stainless steel. The tube sheet is simulated by $6.35 \mathrm{~mm}$ and $12.7 \mathrm{~mm}$ thick collars (OD: $19.05 \mathrm{~mm}$, ID: $6.35 \mathrm{~mm}$ ) also made from corrosion resistant 316L stainless steel. Experiments conducted by Kondo et al. (2009a), (2009b) for fusion reactors suggest that $316 \mathrm{~L}$ stainless steel is a promising candidate material for the CWHE tubes due to its corrosion resistance towards $\mathrm{Li}_{2} \mathrm{BeF}_{4}$ (flibe) foreseen for the air/SCO 2 cooled $\mathrm{FHR}$ design. Similarly promising results were later confirmed by Zheng et al. (2015) who ran their experiments to specifically understand the corrosion behavior in FHR heat exchangers. In addition to the benevolent corrosion behavior of 316L towards flibe Ganesan and Ganesan (1998) examined the relatively good corrosion resistance of annealed 316L towards sodium, another candidate coolant for the reactor design with $\mathrm{S}-\mathrm{CO}_{2}$ cycle. The material composition of the 316L was provided by the vendor in wt\% as following: Fe 58.23-73.61, Cr 16-18.5, C 0-0.08, Mn 0-2, Cu 0-1, Si 0-1, Mo 0-3, P 0-0.045, N 0-0.1, Ti max. 0.7.

Prior to tube expansion the touching surfaces of tube and collar were cleaned in an ultrasonic ethanol bath and rinsed with distilled water. After cleaning, the samples were joined on a manual lathe using a three roller tube expander. Experiments conducted by Sukhawarn and Culvert (1970) indicate advantages performance of three roller tube expanders over expanders with larger amounts of rollers. The tube expander was used with relatively low rotational speed $(<200$ $\mathrm{rpm}$ ) as suggested by the vendor for the used material/tube diameter. Lubricant was used to avoid 
excessive friction that may damage the tool and/or effect the joints quality as described by AlAboodi et al. (2010). Tubes were expanded in a single continues process. A two-stage expansion process as proposed by Yokell (1992) was not applied since sufficient results could be obtained with a simpler one-stage process.

Fig. 1 schematically shows the tube expansion process of the roller tube expander. Three phases:

(a) Insertion phase

(b) Expansion phase

(c) Straightening phase

may be differentiated for the tube expander used here. The tube expander enters the tube with an OD of $4.45 \mathrm{~mm}$ during the insertion phase. During this first phase the tube is loosely, with a certain clearance in the tube sheet. When the tapered mandrel with a taper angle $\alpha$ is pushed towards the tube sheet the tube expanders OD increases to a maximum of $5.38 \mathrm{~mm}$ (expansion phase). In a third phase the tube is straightened when the tube expander rolls reach the untapered end of the mandrel (straightening phase). The roller length of the tube expander was chosen to be larger than the collars thickness so that the transition zone described by Kalnins et al. (1991) and Updike et al. (1992) at which the surface pressure is lower, is outside the tube sheet.

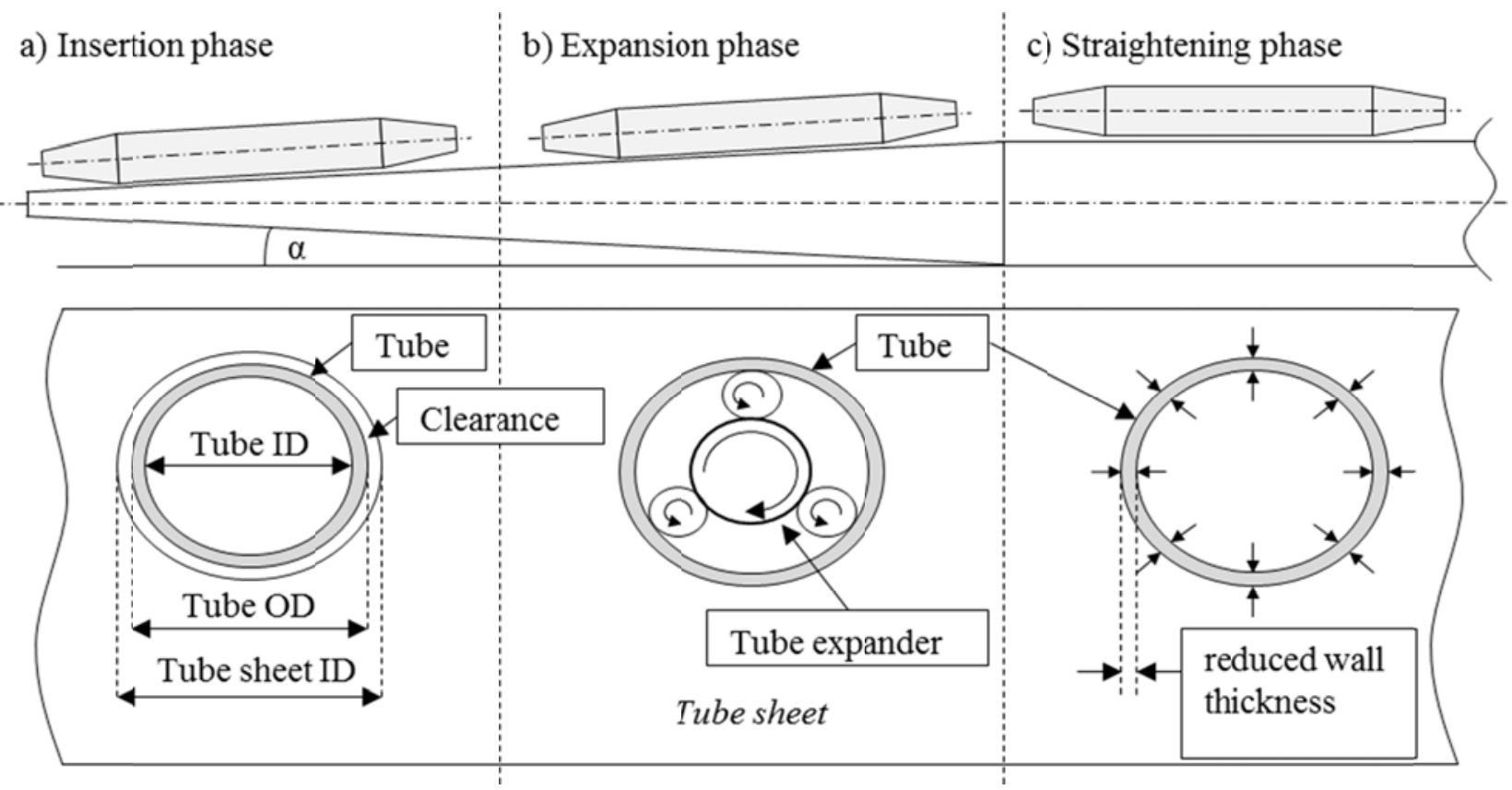

Fig. 1. Schematic illustration of the roller tube expansion process.

Tube-to-tube sheet joint test samples fabricated this way were heat treated in a high vacuum tube furnace at $1,000{ }^{\circ} \mathrm{C}$ for 16 hours excluding one hour ramp up from room temperature and three hours controlled cool down to room temperature. The vacuum was measured to be in the order of $10^{-5} \mathrm{~Pa}$, a range commonly used for diffusion bonding as for instance described by Kazakov (1994) to avoid excessive oxidation. 
In contrast to traditional diffusion bonding described by Kazakov (1994) no additional pressure was applied during the heat treatment. Therefore, the heat treatment was applied longer (approx. 16 hours) than usually recommended (approx. 4 hours) for 316L stainless steel.

The pull-out tests were conducted using a Criterion 43 MTS tensile test system with a max. load capacity of $50 \mathrm{kN}$. When pulled out, force was applied as illustrated in Fig. 2. A plug was inserted (dashed box) to prevent collapsing of the thin walled tube. A two-clamp design as used during pull-out tests by Dethlefs et al. (2014) to evaluate the pull-out force of hybrid friction diffusion bonded aluminum samples was avoided here as such a design may increase the measured pull-out force as a result of the clamp tightening the collar around the tube during testing.

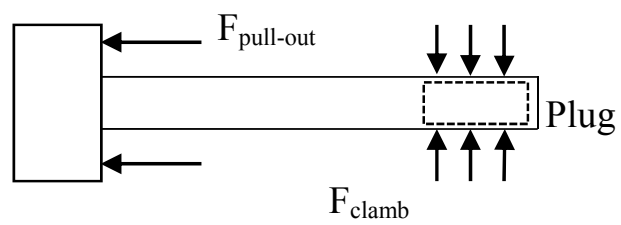

Fig. 2. Illustration of the sample during pull-out testing.

After pull-out testing successful samples were sectioned and the quality of the joints were evaluated using optical microscopy (OM). The samples were cut using a high speed cut off saw and subsequently polished using $\mathrm{SiC}$ grinding paper with 1200 grit in the last step. $0.5 \mu \mathrm{m}$ diamond suspension was used to finalize metallographic polishing. Images of the sectioned samples were obtained with a Zeiss Axio Scope under polarized light.

\section{$3 \quad$ Results and discussion}

3.1 Process development

The experimental procedure described previously generates joints good enough to resist tube pull out and are as such considered successful in this study. Three engineering parameters:

- Applied pressure during tube expansion

- Surface treatment prior to tube expansion

- Time/temperature of the heat treatment

were found to be of particular importance for this novel manufacturing process and are discussed below. Other parameters such as the lubricant viscosity, rotational speed and feed rate of the tube expander, tube thickness and tube/tube sheet material were kept constant during the experiments and are therefore not further discussed here.

\subsubsection{Applied pressure during tube expansion}

Different approaches summarized and discussed by Marré (2009) are proposed to calculate the residual interface pressure between tube and tube sheet. Jawad et al. (1987) proposed an 
approach for tube-to-tube sheet junctions that relates the pull-out force to the residual interface pressure:

$P_{o}=\frac{F \text { pull-out }}{2 \pi f R_{o} L_{e}}$

with

$P_{o} \quad=$ Residual interface pressure between tube and tube sheet

$F_{\text {pull-out }}=$ Force required to pull the tube out of the tube sheet

$f \quad=$ Friction coefficient between tube and tube sheet; estimated to be 0.78 for dry and clean surfaces after (Engineers Handbook 2006)

$L_{e} \quad=$ Length of the bond.

Results obtained by Eq. 1 were compared with a different approach proposed by Yokell (1992) were the residual stress is obtained from the expanding pressure (see Eq. 2) which is estimated using the inner and outer radius of the tube (see Eq. 3).

$P_{o}=P_{e}\left[1-\left(\frac{R_{i}}{R_{o}}\right)^{2}\right]-\left(\frac{2}{\sqrt{3}}\right) \sigma_{y}\left[\ln \left(\frac{R_{o}}{R_{i}}\right)\right]$

$P_{e}=\sigma_{y}\left(1.945-1.384 \frac{R_{i}}{R_{o}}\right)$

with

$P_{e}=$ Expanding pressure after Yokell (1992)

$R_{i}=$ Inner radius of the tube

$R_{o}=$ Outer radius of the tube

$\sigma_{y}=$ Yield strength of the tube as provided by the vendor (206.84 MPa or 30,000 psi)

Results obtained from both approaches are in good agreement (less than $10 \%$ deviation) and estimate the residual stress to be as high as $160.55 \mathrm{MPa}$ (Jawad et al.,1987) and 177.11 MPa (Yokell, 1992) which translates to $77 \%$ or $85 \%$ of the yield strength of the base material assuming uniform touching over the whole area of the bond. The differences between the two methods may be explained by underlying assumptions including: elastic-perfectly plastic material behavior, zero tolerances, uniform expanding pressure and plane stress conditions as pointed out by Shuaib et al. (2003). Furthermore, stainless steel shows considerable springback that has for instance been studied by Tekaslan et al. (2006). Springback is found to be a challenge during tube expansion with roller tube expanders as pointed out by Updike et al. (1992) that is not considered in the above equations.

In addition, the expansion (quantified by the percent wall reduction, WD) is far higher than recommended for commercial tube expansion. Al-Aboodi et al. (2008) point out that the Tubular Exchanger Manufacturer Association (TEMA) recommends a wall reduction of $5 \%$. Shuaib et al. (2003) mention a typical wall reduction of 3 to $12 \%$. To reach residual pressures closer to the yield strength of the base material the tube wall was reduced here by nearly $40 \%$ (tubes and tube 
sheets were measured individually). These high values were achieved using low rotational speed $(<200 \mathrm{rpm})$, low feed (approx. $2.5 \mathrm{~mm} / \mathrm{s})$ and relatively large amounts of lubricant.

Fig. 3 shows three diffusion bonded samples after mechanical pull-out testing that were joint reducing the tube wall by approx. 10, 20 and $30 \%$ (from left to right). All three samples that were produced at the beginning of this study did not fulfill the set requirement as the tube was pulled out of the tube sheet. The different pull-out force resulted in the depicted different elongation of the initially identically long samples.

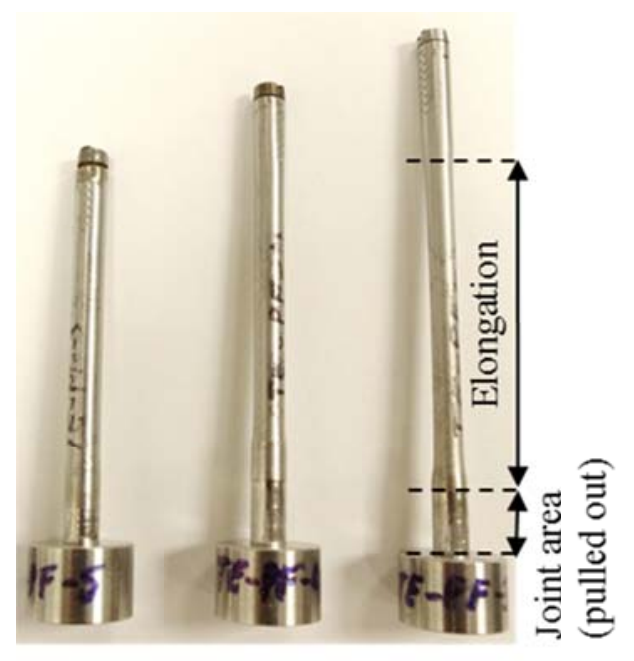

Fig. 3. Test samples joint with different wall reduction (approx. 10, 20 and $30 \%$, from left to right) resulting in different tube elongation before pull-out.

\subsubsection{Surface treatment prior to tube expansion}

Clean surfaces are a basic requirement for diffusion bonding. In addition to simple surface cleaning two subsequent treatments: (1) removal of oxide layer and (2) application of a nickel interlayer were investigated in this work. Kazakov (1994) described how the passive oxide layer that mitigates corrosion of 316L stainless steel (and other materials) needs to be overcome for diffusion bonding to occur. He explains that the constant pressure applied during traditional diffusion bonding breaks the brittle ceramic layer and the applied temperature accelerates its subsequent diffusion into the base material. Since diffusion bonding is performed in a nonoxidizing environment, usually high vacuum or inert gas atmosphere, no new oxide layer can form.

In the process described here pressure is not applied constantly but initially during tube expansion. Since the tube expansion process takes place in an oxidizing environment (air) a new oxide layer forms instantly. For higher quality diffusion bonding woods nickel strike as described by Rudy (2001) with elements from Dang et al. (1993) that seem to work particularly well for $316 \mathrm{~L}$ stainless steel was used. The chemical bath removes the oxide layer and puts a thin nickel strike on the treated surface to mitigate oxidation.

Following the removal of the oxide layer the relevant surfaces were coated using electroless nickel plating as described by Yeh et al. (2000). Kazakov (1994) and more recently Yeh and Chuang (1995) described among many others the increased joint quality when using nickel interlayers during the diffusion bonding process of stainless steel. 
An improved joint quality could only be partially verified with the tube expander process using woods nickel strike and nickel interlayers in a way that tube rupture was achieved with less expanding pressure $P_{e}$ as a result of smaller wall reduction (20-30\% total wall reduction) due to larger clearance used not to damage the treated surfaces. Shuaib et al. (2008) concluded that increasing the clearance up to 10 times of industry standards does not have negative effects on the pull-out force. Improved joint quality due to additional surface treatment may be verified in additional experiments by further reducing the applied pressure or the time and temperature of the heat treatment.

\subsubsection{Time/Temperature of heat treatment}

For diffusion bonding of $316 \mathrm{~L}$ stainless steel with constant pressure applied during the heat treatment a soak time (time of the heat treatment at constant pressure/temperature) of approx. 4 hours is recommended. Previous experience with press fitted and diffusion bonded samples at UCB (UCBTH-14-005, 2014) suggested a soak time of $1000 \mathrm{~min} /$ approx. $16 \mathrm{~h}$ at a temperature of $1000{ }^{\circ} \mathrm{C}$. The approx. 4 times longer soak time required when diffusion bonding pre-stressed joints instead of constantly loaded joints may be due to release of interface normal stress during heat treatment.

To make the process more economical shorter soak times were investigated under constant temperature $\left(1000{ }^{\circ} \mathrm{C}\right)$. To allow tube pull-out to occur the tube sheet length was reduced from $12.7 \mathrm{~mm}$ to $6.35 \mathrm{~mm}$ reducing the potential bonding area by $50 \%$. A linear relationship of the pull-out force between expanded but not heat treated samples with a tube sheet thickness of 6.35 $\mathrm{mm}$ and $12.7 \mathrm{~mm}$ was observed as part of this study. This allowed reducing the tube sheet thickness from $12.7 \mathrm{~mm}$ to $6.35 \mathrm{~mm}$, while obtaining comparable results beyond tube rupture.

7 batches with 3 samples per batch were manufactured as described above. Surfaces were cleaned, no additional interlayer was used. Samples were heat treated for 0 (reference group), 1, 2, 4, 8, 12 and 16 hours excluding 1 hour ramp up to operating temperature and 3 hours controlled cool down to room temperature. Results are summarized in Fig. 4.

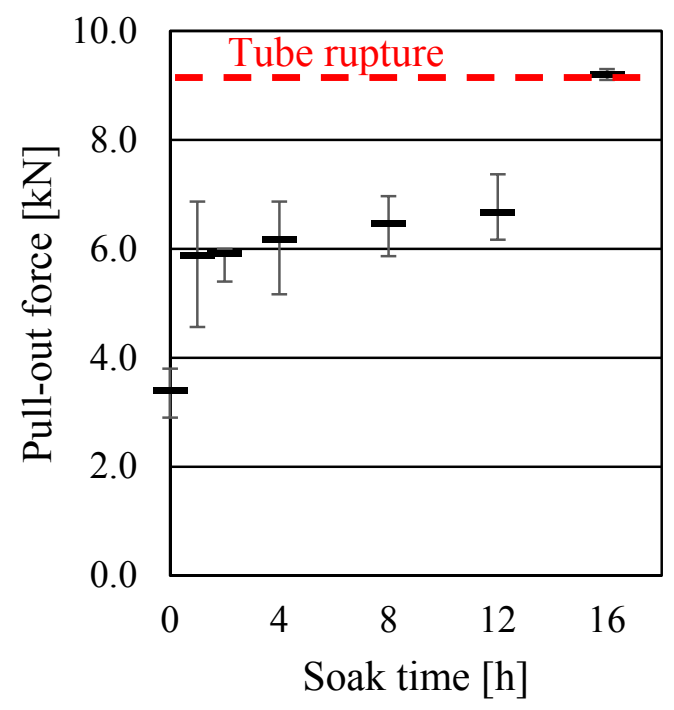

Fig. 4. Mean pull-out force of test sample batch à three samples with $6.35 \mathrm{~mm}$ thick tube sheet heat treated with varying soak times: $0,1,2,4,8,12,16$ hours. 
Tube rupture occurs at approx. $9.2 \mathrm{kN}$ and is indicated by the dashed red line. Mechanical pull out tests of samples heat treated for 16 hours resulted in tube rupture. Samples heat treated for less than 16 hours were pulled out at varying force with a slight trend towards higher pull out force with longer soak time. Reference samples without heat treatment were pulled out at a mean pull-out force of $3.4 \mathrm{kN}$. Effects of different temperatures have not been investigated in this study.

\subsection{Mechanical pull-out tests}

Mechanical pull-out tests were performed with test samples as the major criteria to judge the quality of the bond. Samples were considered successful in case of tube rupture. Annealed 316L stainless steel has an ultimate tensile strength of min. $515 \mathrm{MPa}$ at room temperature which translates well to the approx. $9.2 \mathrm{kN}$ force measured for successful samples prior to tube rupture. A linear relationship between the thickness of the tube sheet resulting in a different potential bonding area and the pull-out force could be established for not heat treated samples with tube sheet thickness of 6.35 and $12.7 \mathrm{~mm}$. It was found that diffusion bonding subsequent to tube expansion increases the pull-out force nearly threefold from a mean of $3.4 \mathrm{kN}$ to $9.2 \mathrm{kN}$. At 9.2 $\mathrm{kN}$ the tube ruptures so that possible higher pull-out forces could not be measured anymore. These findings are graphically shown in Fig. 5.

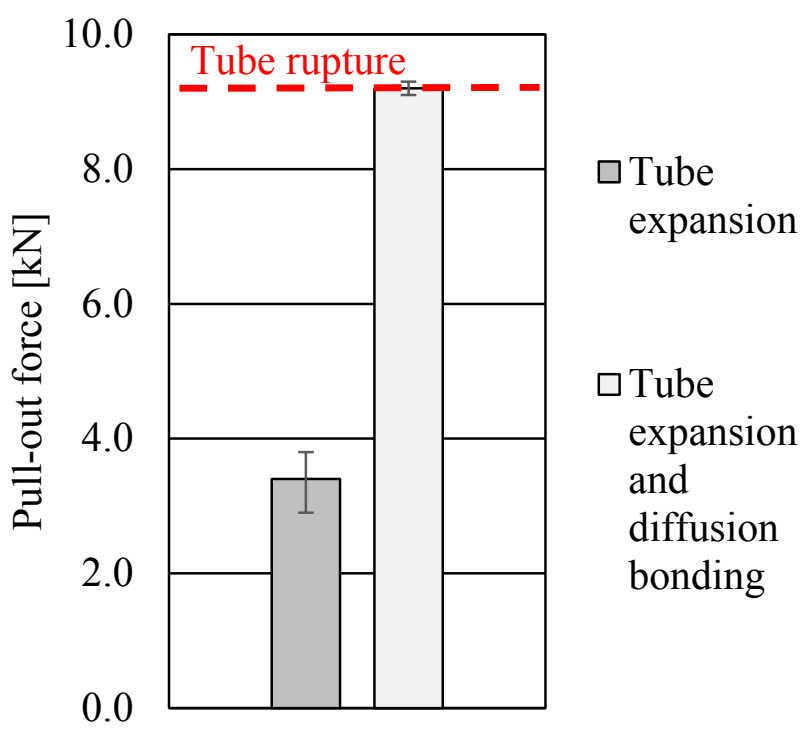

Fig. 5. Mean pull-out force of expanded as well as expanded and diffusion bonded test samples.

\subsection{Qualitative analysis}

Successful samples have been sectioned and analyzed using OM. It was found that although the process fulfills the engineering requirements only partial diffusion bonding, characterized by dissimilar microstructures of the tube and the tube sheet occurs. Fig. 6 shows three OM pictures of a test sample in which the tube expander was only partially inserted to better understand the 
effects of the expansion process and the obtained results. Fig. 6a shows an area that was not expanded characterized by the relatively large visible gap between tube and tube sheet, Fig. $6 \mathrm{~b}$ shows a partially expanded area reached by the tube expander tip and Fig. 6c shows a fully expanded area characterized by no visible gap between tube and tube sheet.

Tube and tube sheet material was obtained with different microstructures that can be identified in Fig. 6a. Smaller grains as a result of work hardening can be identified in both the tube and the tube sheet and are depicted in Fig. $6 \mathrm{~b}$ and more pronounced in Fig. 6c.

Partial diffusion bonding were some grains grew over the initial bonding area can be found in Fig. 6c. Results of press fitted and diffusion bonded samples presented by Haneklaus et al. (2016) indicate that joints obtained using tube expansion and diffusion bonding can be further improved.

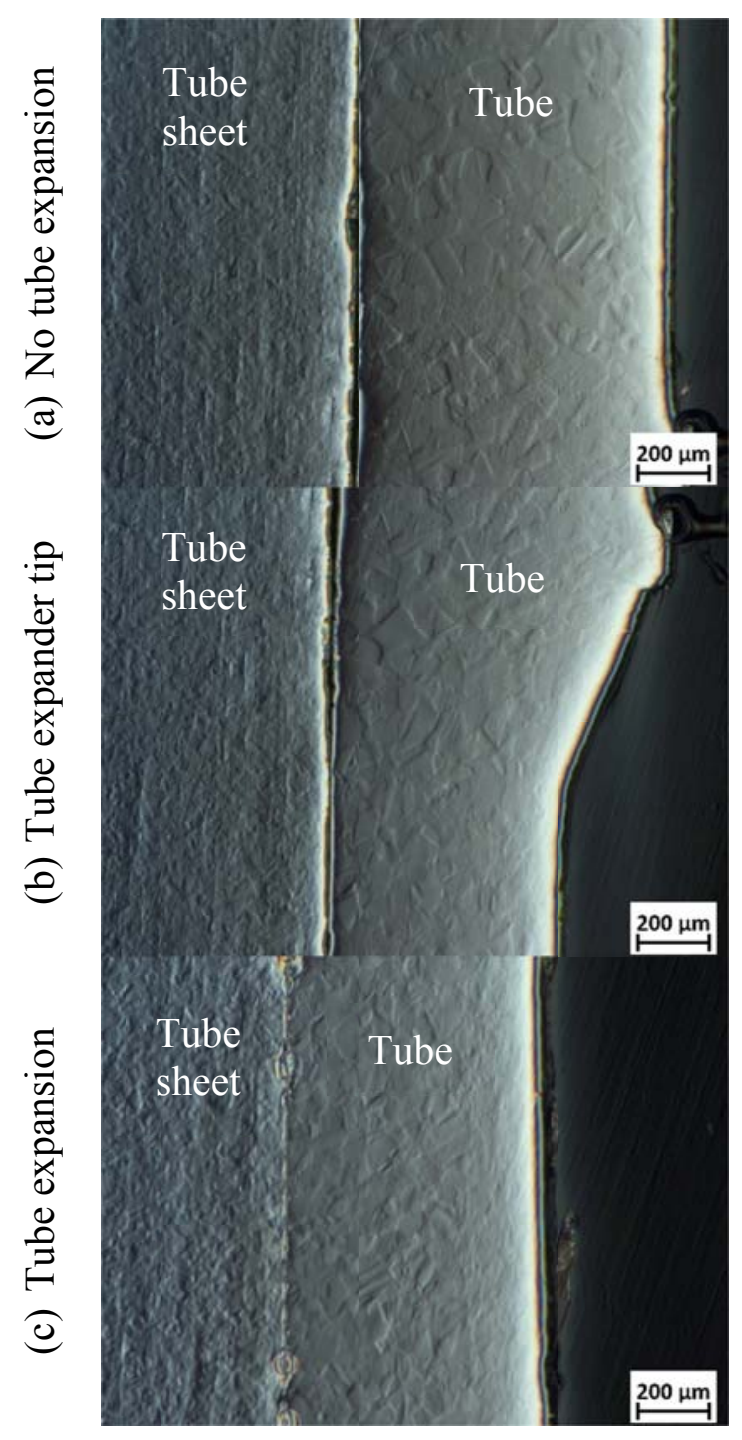

Fig. 6. Optical microscopy pictures of a diffusion bonded test sample: (a) no tube expansion, (b) tube expander tip and (c) tube expansion. 


\section{Conclusions}

This study presented a tube expansion process with subsequent diffusion bonding using a commercial three roller tube expander. The following conclusions were obtained:

- A linear relationship between the thickness of the tube sheet resulting in a different potential bonding area and the pull-out force could be established for not heat treated samples with tube sheet thickness of 6.35 and $12.7 \mathrm{~mm}$.

- It was found that diffusion bonding subsequent to tube expansion increases the pull-out force nearly threefold from a mean of $3.4 \mathrm{kN}$ to $9.2 \mathrm{kN}$. At $9.2 \mathrm{kN}$ the tube ruptures so that possible higher pull-out forces could not be measured anymore.

- Relatively large wall reduction during tube expansion of up to $40 \%$ achieved with relatively low rotational speed $(<200 \mathrm{rpm})$ and feed (approx. $2.5 \mathrm{~mm} / \mathrm{s})$ usually not recommended for roller tube expanders increases the pull-out force after diffusion bonding.

- Removal of the passive oxide layer as well as introduction of an additional nickel interlayer may increase the joints quality against pull-out but certainly does not decrease the joints quality against pull-out. (A clear relationship could not be established since the tube ruptured in both cases).

- Soak times four times longer (approx. 16 hours total) than usually recommended for diffusion bonding of stainless steel with pressure applied constantly during the process provide best results against tube pull-out when compared to shorter soak times $(0,1,2,4$, 8 and 12 hours).

- Mechanical pull-out tests were conducted successfully in a way that the joint outperformed the tube, which was the main requirement for this process.

- Qualitative analysis of the bond using OM revealed that partial diffusion bonding characterized by no visible gap between the joint parts but visible difference in microstructure of the parts occurred.

\section{Acknowledgment}

The authors want to express their gratitude to the operators of the mechanical engineering machine shop at UCB without whose guidance this work would have not been possible.

This research is performed using funding received from the U.S. Department of Energy Office of Nuclear Energy's Nuclear Energy University Programs. The views expressed have not been endorsed by the supporting agencies. Any remaining errors, omissions, or inconsistencies are the authors' alone. 


\section{References}

Al-Aboodi A. et al. 2008. Modeling the Effects of Initial Tube-Tubesheet Clearance, Wall Reduction and Material Strain Hardening on Rolled Joint, J. Press. Vessel Technol., vol. 130, 041204.

Al-Aboodi A. et al., 2010. Effects of friction on roller expanded tube - tubesheet joint strength joint strength, Int J Mater Form, DOI 10.1007/s12289-010-0686-3.

Dang A. et al., 1993. The colectrodedeposition of raney nickel alloy powder on a stainless steel grid, J. Hydrogen Energy, vol. 18, no. 11, pp. 941-944.

Dethlefs A. et al., 2014. Hybrid friction diffusion bonding of aluminium tube-to-tube-sheet connections in coil-wound heat exchangers, Mater. Des., vol. 60, pp. 7-12.

Engineers Handbook 2006. http:/www.engineershandbook.com/Tables/frictioncoefficients.htm, accessed 3/1/2016.

Forsberg C. W. et al., 2003. Molten-salt-cooled Advanced High Temperature Reactor for Production of Hydrogen and Electricity, Nucl. Technol., vol. 144, pp. 289-302.

Ganesan V. and Ganesan V., 1998. Corrosion of annealed AISI 316 stainless steel in sodium environment, J. Nucl. Mater., vol. 256, no. 1, pp. 69-77.

Haneklaus N. et al., 2015. Diffusion Bonding of 316 SS Tube-to-Tube Sheet Joints using a commercial Tube Expander, 2015 ANS Winter Meeting and Nuclear Expo, Washington D.C., USA, November 8-12.

Haneklaus N. et al., 2016. Development of Engineering Parameters for Low Pressure Diffusion Bonds of 316 SS Tube-to-Tube Sheet Joints for FHR Heat Exchangers, 2016 The Minerals, Metals \& Materials Society Annual Meeting \& Exhibition (TMS2016), Nashville, USA, February 14-18.

Jawad M.H. et al., 1987. Evaluation of Tube-to-Tubesheet Junctions, J. Press. Vessel Technol., vol. 109, pp. 19-26.

Kalnins A. et al., 1991. Contact pressure in rolled tube-tubesheet joints, Nuclear Engineering and Design, vol. 130, pp. 229-234.

Kazakov N., 1994. Diffusion bonding of materials, Pergamon, Oxford.

Kikuchi H. et al., 2010. The Progress of R\&Ds for JSFR innovative Technologies, $18^{\text {th }}$ International Conference on Nuclear Engineering (ICONE18), Xi'an, China, May 17-21. 
Kondo M. et al., 2009a. Corrosion characteristics of reduced activation ferritic steel, JLF-1 (8.92Cr-2W) in molten salts Flibe and Flinak, Fusion Eng. Des., vol. 84, no. 7-11, pp. 10811085.

Kondo M. et al., 2009b. Metallurgical study on corrosion of austenitic steels in molten salt LiFBeF2 (Flibe), J. Nucl. Mater., vol. 386-388, pp. 685-688.

Marré M., 2009. Grundlagen der Prozessgestaltung für das Fügen durch Weiten mit Innenhochdruck, PhD-Thesis.

Massey K.M. and Jones M.W., 2012. Tube Pullout Testing Experience, $20^{\text {th }}$ International Conference on Nuclear Engineering (ICONE20), Anaheim, CA, USA, July 30 - August 3.

Rudy S.F., 2001. Surface preparation of various metals and alloys before plating and other finishing applications, Metal Finishing, vol 99, pp. 191-205.

Shuaib A.N. et al., 2003. Experimental Investigation of Heat Exchanger Tubesheet Hole Enlargement, J. Press. Vessel Technol., vol. 125, no. February 2003, pp. 19-25.

Shuaib A.N. et al., 2008. Integrity of Roller-Expanded Tube-to-Tubesheet Joints with Overenlarged Tubesheet Holes, J. Press. Vessel Technol., vol. 130, no. February 2008, pp. 259265.

Sukhawarn P. and Culvert L.E., 1970. Expander Design in the Tube Expanding Process: The Influence of the Number of Rollers, Journal Mechanical Engineering Science, vol. 12, pp. 30-36.

Tekaslan Ö. et al., 2006. Determining springback amount of steel sheet metal has $0.5 \mathrm{~mm}$ thickness in bending dies, Mater. Des., vol. 27, no. 3, pp. 251-258.

UCBTH-14-002, 2014. Technical Description of the "Mark 1" Pebble-Bed Fluoride-Salt-Cooled High-Temperature Reactor (PB-FHR) Power Plant, University of California, Berkeley, Nuclear Engineering Department.

UCBTH-14-005, 2014. Design, Manufacture, Modeling and Testing of 316 SS Diffusion Bonded Tube-sheet Joints and In-Service Inspection Methods for the Mk1 PB-FHR CTAHs, University of California, Berkeley, Nuclear Engineering Department.

Updike D. P. et al., 1992. Residual Stresses in Transition Zones of Heat Exchanger Tubes, J. Press. Vessel Technol., vol. 114, no. May 1992, pp. 149-156.

Yeh M. S. and Chuang T. H., 1995. Low-pressure diffusion bonding of SAE 316 stainless steel by inserting a superplastic interlayer, Scr. Metall. Mater., vol. 33, no. 8, pp. 1277-1281.

Yeh M.S. et al., 2000. Diffusion Bonding of a Superplastic Inconel 718SPF Superalloy by Electroless Nickel Plating, J. Mater. Eng. Perform., vol. 9, no. 1, pp. 51-55. 
Yokell S., 1992. Expanded, and Welded-and-Expanded Tube-to-Tubesheet Joints, J. Press. Vessel Technol., vol. 114, no. May 1992, pp. 157-165.

Zheng G. et al., 2015. Corrosion of 316 stainless steel in high temperature molten Li2BeF4 (FLiBe) salt, J. Nucl. Mater., vol. 461, pp. 143-150. 